\section{Relevant Research}

\section{Evidence-based decision making is a hot issue these days, and if you're reading this journal, you're probably already committed to the idea of using research evidence in your work.}

It's not that the only problem in running the health system is an information gap. And research will never be all you need to make a decision, or the only factor you consider. But research can help you make decisions, evaluate their feasibility and potential impact.

The Canadian Health Services Research Foundation has developed a self-assessment tool for decision makers to help them define and assess their organization's use of research. First tested in Calgary in September 2000, it is still in development. Essentially a questionnaire, the purpose of the self-assessment tool is to let decision makers identify strengths and weaknesses in research use and give ideas for how to use research more effectively in the future.

The self-assessment is divided into four areas - how you acquire evidence (Can the organization find the evidence it needs?), how you assess it (Can you assess whether research is reliable and high-quality and whether it is relevant and applicable?), how you adapt its format (Can you present the evidence to decision makers in a useful format, which synthesizes recommendations?) and how you apply it in making decisions (Do you have the skills, structures, processes and corporate culture to promote and use research evidence in decision-making?).

Because this is an organizational assessment, it's best if a cross-organizational team - perhaps including senior managers, members of the board and front-line workers - does it collectively. It's not a test; there are no right or wrong answers. But used properly it should be a catalyst for discussion on research use: what the organization is doing right and what more it needs to do.

More information is available from: Michelle Campbell, assistant director, knowledge transfer, Canadian Health Services Research Foundation, (613) 728-2238, campbellm@chsrf.ca

\section{www.chsif.ca}

\section{H ospital Quarterly}

Hospital Quarterly provides evidence-based best practices, analysis of leading edge developments and announcements of key policy and administrative decisions from government. It is the authoritative voice for the healthcare administrator and executive providing acute care, rehabilitation, long-term care, home care, e-care, as well as policies and funding. Hospital Quarterly provides a direct link to peers and their management challenges and best practices. Now in the works, for example, is a comprehensive series on best practices to ensure the health of our communities. This will deal with issues from environmental child abuse to healthy hospitals and healthy communities and resources such as water. Look for strategies to manage the impact of other social and economic determinants that extend beyond traditional healthcare.

We will continue our series on Error in Health Care; CIHI's analyses of the meaning of data for health administrators; innovative HR strategies. And we review the web, present the latest research from POLLARA, ICES and CHSRF and always present the important details of consumer trends from the Berger Monitor.

Editor is Dr. Peggy Leatt of the University of Toronto

\section{HealthcarePapers}

HealthcarePapers is the leading journal for Canadians examining new policies for the new healthcare. Each issue is dedicated to one policy question.

Subscribers can access these 2000/2001 back issues:

- Primary Care

- Integration of Health Care

- Medicare

- Home Care

- Health System Error/Patient Safety

Here is what we are currently working on:

- Rationing at the Bedside

- Academic Health Science Centres - new roles and opportunities

- The Right to Choose! - consumer choices in healthcare

- Drugs - accessibility, availability and appropriateness

And we are planning these issues:

- Human Resource Management - crisis management or new models

- Diversity in Healthcare - Are we meeting expectations?

- Alternative Therapies/Complementary Medicine - Collaboration?

Competition?

- Physician Compensation

Editor is Dr. Peggy Leatt of the University of Toronto

\section{The journal of ElectronicH ealthcare.com}

The journal of ElectronicHealthcare.com looks at e-models, e-practices and e-products for e-health. It presents important planning considerations, policy recommendations and best practices for all sectors in healthcare.

Board members include representatives from:

Canadian Institute of Health Information (Mr. Richard Alvarez)

Canadian Society of Telehealth and Hospital for Sick Children (Dr. Robert Filler)

Health Canada (Mr. William Pascal)

Health Information Management Systems Society (Ms. Lina Milone)

HealthLink Clinical Data Network (Dr. Michael Guerriere)

Hospital Quarterly and HealthcarePapers (Dr. Peggy Leatt)

London Health Sciences Centre and St. Joseph's Healthcare (Ms. Diane Beattie)

Mount Sinai Hospital (Dr. Lynn Nagle)

Ontario Hospital Association (Mr. Warren DiClemente)

Ottawa Hospital (Mr. Victor Simon)

Providence Healthcare - Vancouver (Ms. Carla Gregor)

School of Policy Studies - Queens University (Dr. Duncan Sinclair)

Universities of Surrey and Erasmus (Dr. Victor Peel)

University Health Network (Mr. Matthew Anderson)

University of Toronto (Dr. Vivek Goel)

University of Toronto (Professor Tina Smith)

University of Victoria (Professor Denis Protti) 